\title{
GAMBARAN NILAI ANKLE BRACHIAL INDEX (ABI) PADA PENYANDANG DM TIPE 2 DI PUSKESMAS GUNUNGSARI LOMBOK BARAT
}

\author{
Bahjatun Nadrati ${ }^{1}$, Zuhratul Hajri² ${ }^{2}$ Sri Suharti ${ }^{3}$
}

1Program Studi D.III Keperawatan STIKES YARSI Mataram, Indonesia. Email: bahjatun.nadrati.bn@gmail.com 2Program Studi D.III Keperawatan STIKES YARSI Mataram, Indonesia. Email: riehaji@ @gmail.com 3Akademi Keperawatan Baitul Hikmah Bandar Lampung, Indonesia. Email: srisuharti1977@gmail.com

\section{ABSTRACT: THE ANKLE BRACHIAL INDEX AMONG PATIENTS WITH TYPE 2 DIABETES IN WEST LOMBOK-INDONESIA}

Background: Diabetes spreads throughout the provinces in Indonesia. One of them in the Province of West Nusa Tenggara (NTB), the prevalence of DM diagnosed is $0.9 \%$ of the total population. Peripheral vascularization disturbance that occur in people with DM need to be known from the beginning. One effort to determine the existence of disorders peripheral vascularization is by examining the ankle brachial index ( $A B I)$.

Purpose: To determine the description of the value of the Ankle Brachial Index (ABI) of people with DM in the DM group.

Methods: Descriptive study with a population of 25 patients with a total sampling technique. The instrument used is the observation sheet.

Results: Most women with DM were as many as 17 patients (68\%), most people with DM at the age of 46 - 55 years $(68 \%)$, the value of $A B I$ with $D M$ with normal interpretations of the right $A B I 22$ patients $(88 \%)$ and left $A B I$ 23 patients $(92 \%)$, right borderline perfusion $A B I$ occurred at the age of $56-65$ years as many as 2 patients $(66.7 \%)$, borderline perfusion left $A B \mid$ occurred at the age of $56-65$ years as many as 2 patients $(100 \%)$, borderline perfusion Right $A B I$ occurred in 2 female respondents $(66.7 \%)$, borderline perfusion left $A B I$ occurred in female respondents as many as 2 patients $(100 \%)$.

Conclusion: In an effort to improve the health status of the community, especially DM persons, it is expected that the Gunung Sari Health Center in West Lombok Regency can control people with DM in participating in the Puskesmas program, especially DM.

\section{Keywords: Ankle Brachial Index (ABI), Type 2 Diabetes}

Pendahuluan: Penyakit diabetes menyebar diseluruh provinsi di Indonesia. Salah satunya di Provinsi Nusa Tenggara Barat (NTB), prevalensi DM yang sudah terdiagnosis adalah $0,9 \%$ dari jumlah total penduduk. Gangguan vaskularisasi perifer yang terjadi pada penyandang DM perlu diketahui dari awal. Salah satu upaya untuk mengetahui adanya gangguan vaskularisasi perifer adalah dengan melakukan pemeriksaan ankle brachial index $(A B I)$.

Tujuan : Mengetahui gambaran nilai Ankle Brachial Index $(A B)$ penyandang DM pada kelompok penyandang DM.

Metode : Penelitian deskriptif dengan populasi 25 pasien dengan teknik pengambilan sampel total sampel. Instrumen yang digunakan adalah lembar observasi.

Hasil penelitian: Penyandang DM terbanyak dialami oleh perempuan yaitu sebanyak 17 pasien $(68 \%)$, penyandang DM terbanyak pada usia 46 - 55 tahun (68\%), nilai $A B I$ penyandang DM dengan interpretasi normal $A B I$ kanan 22 pasien (88\%) dan $A B I$ kiri 23 pasien (92\%), borderline perfusion $A B I$ kanan terjadi pada usia 56 65 tahun yaitu sebanyak 2 pasien $(66,7 \%)$, borderline perfusion $A B I$ kiri terjadi pada usia $56-65$ tahun sebanyak 2 pasien (100\%), borderline perfusion $\mathrm{ABI}$ kanan terjadi pada responden perempuan sebanyak 2 pasien $(66,7 \%)$, borderline perfusion ABI kiri terjadi pada responden perempuan sebanyak 2 pasien $(100 \%)$.

Simpulan: Dalam upaya untuk meningkatkan derajat kesehatan masyarakat khususnya penyandang DM diharapkan Puskesmas Gunung sari Kabupaten Lombok Barat, dapat mengontrol penyandang DM dalam mengikuti program puskesmas khususnya DM.

Kata kunci: Ankle Brachial Index (ABI), Diabetes Melitus (DM) Tipe 2. 


\section{PENDAHULUAN}

Sampai saat ini penyakit Diabetes Melitus (DM) merupakan suatu kelompok penyakit metabolik yang dikarakteristikkan dengan tingginya kadar glukosa di dalam darah (hiperglikemia) karena kelainan sekresi insulin, kelainan kerja insulin, atau kedua-duanya, American Diabetes Association (Yuliani, Oenzil \& Iryani 2014; Wahyuni, 2015).

DM mempunyai dua tipe utama, yaitu DM tipe 1 (DMT1) yang diakibatkan oleh kerusakan sel $\beta$, biasanya menyebabkan kekurangan insulin yang absolut, dan DM tipe 2 (DMT2) yang disebabkan karena resistensi insulin (reseptor insulin mengalami gangguan) defisiensi insulin relatif atau karena defek sekresi insulin disertai resistensi insulin (Suriya, 2016; Wijay, 2013).

DM menempati urutan keempat dari sepuluh penyakit tidak menular (PTM) di Indonesia dengan prevalensi $1.5 \%$. Penyakit diabetes menyebar diseluruh provinsi di Indonesia. Salah satunya di Provinsi Nusa Tenggara Barat (NTB), prevalensi DM yang sudah terdiagnosis adalah 0,9\% dari jumlah total penduduk (Riskesdas, 2013). Kabupaten lombok barat merupakan salah satu kabupaten yang ada di Provinsi NTB yang terdiri dari 10 kecamatan yang dengan prevalensi penyandang DM sebesar $1.5 \%$ sesuai degan hasil diagnosis tenaga kesehatan dan berdasarkan gejala (Mongisidi, 2014; Toharin \& Kes, 2015; Oemiyati \& Rustika, 2015; Ghani, Susilawati, \& Novriani, 2016; Riskesdas 2007).

Roglic, et al. (2005) dalam penelitiannya mengemukakan bahwa DM merupakan salah satu penyakit serius yang dapat menimbulkan berbagai komplikasi dan menyebabkan kematian (Rahayu, Kamaluddin \& Sumarwati, 2014; Widayati, 2015; Firdaus, 2014).

Komplikasi yang sering timbul pada penyandang DM dapat bersifat akut maupun kronik (komplikasi jangka panjang) (Wulandari \& Martini 2013; Hidayati \& Sitorus, 2014; Rahayu \& Widastra 2014). Komplikasi kronik tersebut akan menyebabkan gangguan pada aliran pembuluh darah perifer ke kaki pada penyandang DM, sehingga akan memunculkan masalah keperawatan. Salah satu masalah keperawatan yang dapat ditimbulkan dari gangguan aliran pembuluh darah perifer ke kaki adalah ketidak efektifan perfusi jaringan perifer. Masalah ini terjadi karena penurunan oksigen dalam darah yang mengakibatkan kegagalan penghantaran nutrisi ke jaringan pada tingkat kapiler yang terjadi karenapeningkatan vikositas darah akibat hiperglikemia (Apriliyana \& Husada 2015; Posisi, 2005).

Penurunan sirkulasi ke perifer merupakan salah satu penyebab terjadinya ulkus diabetik yang disebabkan oleh penurunan suplai oksigen dan nutrient sehingga menyebabkan luka gangren pada kaki (Amalia, 2016; Restuningtyas; Widyawati, Irawaty \& Sabri, 2017)

Gangguan vaskularisasi perifer yang terjadi pada penyandang DM perlu diketahui dari awal. Salah satu upaya untuk mengetahui adanya gangguan vaskularisasi perifer adalah dengan melakukan pemeriksaan ankle brachial index $(A B I) . A B I$ merupakan suatu pemeriksaan non invasive untuk mengetahui vaskularisasi ke arah kaki dengan mengukur rasio tekanan darah sistolik (ankle) dengan tekanan darah sistolik lengan (brachial). Dimana yang dikatakan terjadinya penurunan aliran darah ke perifer jika didapatkan nilai $A B /<0.9$ dan dikatan $A B I$ normal dengan nilai $\geq$ 1.0-1.2 (Clayton \& Tom 2009; Williams \& Wilkins, 2011).

Puskesmas Gunungsari merupakan salah satu dari 17 Puskesmas yang ada di Kabupaten Lombok Barat sebagai tempat masyarakat mencari pelayanan kesehatan yang salah satunya oleh penyandang DM. Dimana prevalensi penyakit DM yang ada di wilayah kerja Puskesmas Gunungsari ataupun dari luar wilayah kerja Puskesmas Gunungsari yang datang berobat sebesar 1.231 (Data Puskesmas Gunungsari). Survey pendahuluan yang dilakukan peneliti melalui observasi dan wawancara kepada ketua penanggung jawab kelompok penyandang DM di Puskesmas Gunungsari di dapatkan bahwa tidak ada data yang pasti tentang gangguan vaskuler di kaki pada penyandang DM. Namun pada beberapa penyandang DM mengeluhkan adanya kaki yang terasa nyeri, baal, dan kulit kakinya yang menghitam. Gejala ini merupakan gejala pada gangguan vaskuler.

Adapun tujua penelitian ini adalah mengetahui gambaran nilai Ankle Brachial Index $(A B I)$ penyandang DM pada kelompok penyandang DM di Puskesmas Gunungsari Kabupaten Lombok Barat

Bahjatun Nadrati' Program Studi D.III Keperawatan STIKES YARSI Mataram, Indonesia Email: bahjatun.nadrati.bn@gmail.com

Zuhratul Hajri ${ }^{2}$ Program Studi D.III Keperawatan STIKES YARSI Mataram, Indonesia. Email: riehajri@gmail.com Sri Suharti ${ }^{3}$ Akademi Keperawatan Baitul Hikmah Bandar Lampung, Indonesia. Email: srisuharti1977@gmail.com 


\section{METODE PENELITIAN}

Rancangan penelitian yang digunakan dalam penelitian ini adalah penelitian deskriptif yang bertujuan untuk mendeskripsikan (memaparkan) fenomena / peristiwa - peristiwa penting yang terjadi pada masa kini.

Penelitian ini dilakukan pada April 2018 di Puskesmas Gunungsari Kabupaten Lombok Barat. Populasi penelitian ini adalah seluruh pasien penyandang DM yang mengikuti program Prolanis diPuskesmas Gunungsari Lombok Barat dengan teknik total sampling sebanyak 25 responden. Instrumen yang digunakan dalam penelitian ini lembar observasi. Dimana tekanan darah pasien diukur pada bagian lengan dan kaki. Analisa yang digunakan adalah analisa univariat.

\section{HASIL}

\section{Tabel 1 Distribusi Frekuensi Responden Berdasarkan Jenis Kelamin N=25}

\begin{tabular}{ccc}
\hline $\begin{array}{c}\text { Jenis } \\
\text { Kelamin }\end{array}$ & Frekuensi & $\mathbf{( \% )}$ \\
\hline Laki-laki & 8 & $32 \%$ \\
Perempuan & 17 & $68 \%$ \\
Jumlah & $\mathbf{2 5}$ & $\mathbf{1 0 0 \%}$ \\
\hline
\end{tabular}

Dari tabel 1 di atas, dapat dilihat bahwa sebagian besar responden yang mengalami DM berjenis kelamin perempuan yaitu sebanyak 17 orang $(68 \%)$.

Tabel 2 Distribusi Frekuensi Responden Berdasarkan Umur N=25

\begin{tabular}{ccc}
\hline $\begin{array}{c}\text { Kelompok Umur } \\
\text { (tahun) }\end{array}$ & Frekuensi & $\mathbf{( \% )}$ \\
$36-45$ & 4 & $16 \%$ \\
$46-55$ & 17 & $68 \%$ \\
$56-65$ & 4 & $16 \%$ \\
Jumlah & $\mathbf{2 5}$ & $\mathbf{1 0 0 \%}$ \\
\hline
\end{tabular}

Dari tabel 2 di atas, didapatkan bahwasebagian besar responden berada pada kelompok usia 46 - 55 tahun yaitu sebnayak 17 orang $(68 \%)$.

Tabel 3. Distribusi Frekuensi Nilai ABI Kanan Penyandang DM N=25

\begin{tabular}{|c|c|c|}
\hline Interpretasi ABI & Frekuensi & $(\%)$ \\
\hline Normal & 22 & $88 \%$ \\
\hline $\begin{array}{l}\text { Borderline } \\
\text { Perfusion }\end{array}$ & 3 & $12 \%$ \\
\hline Iskemik Berat & 0 & $0 \%$ \\
\hline Iskemik Kaki Kritis & 0 & $0 \%$ \\
\hline Jumlah & 25 & $100 \%$ \\
\hline
\end{tabular}

Dari tabel 3 di atas, didapatkan bahwa hampir seluruh responden berada pada nilai $A B I$ normal yaitu sebaayak 22 orang (88\%). 
GAMBARAN NILAI ANKLE BRACHIAL INDEX (ABI) PADA PENYANDANG DM TIPE 2 DI PUSKESMAS GUNUNGSARI LOMBOK BARAT

Tabel 4. Distribusi Frekuensi Nilai ABI Kiri Penyandang DM N=25

\begin{tabular}{lcc}
\hline Interpretasi ABI & Frekuensi & $\mathbf{( \% )}$ \\
\hline Normal & 23 & $92 \%$ \\
Borderline & 2 & $8 \%$ \\
Perfusion & 0 & $0 \%$ \\
Iskemik Berat & 0 & $0 \%$ \\
Iskemik Kaki Kritis & $\mathbf{2 5}$ & $\mathbf{1 0 0 \%}$ \\
\hline \multicolumn{1}{c}{ Jumlah } & &
\end{tabular}

Dari tabel 4 di atas, didapatkan bahwa hampir seluruh responden berada pada nilai $A B I$ normal yaitu sebnayak 23 orang (92\%).

Tabel 5. Distribusi Frekuensi Nilai ABI Kanan Penyandang DM Berdasarkan Usia N=25

\begin{tabular}{ccccccc}
\hline Usia & \multicolumn{4}{c}{ ABI Kanan } & \multirow{2}{*}{ Total } \\
\cline { 2 - 5 } & \multicolumn{1}{c}{ Normal } & \multicolumn{3}{c}{$\begin{array}{c}\text { Borderline } \\
\text { perfusion }\end{array}$} & \\
\cline { 2 - 6 } & $\mathbf{f}$ & $\%$ & $\mathrm{f}$ & $\%$ & $\mathrm{~F}$ & $\%$ \\
\hline $36-45$ & 3 & 13, & 1 & 33, & 4 & 16,0 \\
& & 6 & & 3 & & \\
$46-55$ & 17 & 77, & 0 & 0 & 17 & 68,0 \\
& & 3 & & & & \\
$56-65$ & 2 & 9,1 & 2 & 66, & 4 & 16,0 \\
& & & 7 & & \\
Total & $\mathbf{2 2}$ & $\mathbf{1 0 0}$ & $\mathbf{3}$ & $\mathbf{1 0 0}$ & $\mathbf{2 5}$ & $\mathbf{1 0 0}$ \\
\hline
\end{tabular}

Dari tabel 5 di atas, didapatkan bahwa borderline perfusion terjadi pada usia 56 - 65 tahun yaitu sebanyak 2 orang $(66,7 \%)$.

Tabel 6. Distribusi Frekuensi Nilai ABI Kiri Penyandang DM berdasarkan Usia N=25

\begin{tabular}{ccccccc}
\hline Usia & \multicolumn{4}{c}{ ABI Kiri } & \multirow{2}{*}{ Total } \\
\cline { 2 - 5 } & Normal & \multicolumn{3}{c}{$\begin{array}{c}\text { Borderline } \\
\text { perfusion }\end{array}$} \\
& \multicolumn{5}{c}{ f } & \\
\cline { 2 - 6 } & f & f & $\%$ & F & $\%$ \\
\hline $36-45$ & 4 & 17, & 0 & 0 & 4 & 16, \\
& & 4 & & & & 0 \\
$46-55$ & 17 & 73, & 0 & 0 & 17 & 68, \\
& & 9 & & & & 0 \\
$56-65$ & 2 & 8,7 & 2 & 100 & 4 & 16, \\
& & & & & 0 \\
Total & 23 & 100 & 2 & 100 & 25 & 100 \\
\hline
\end{tabular}

Dari tabel 6 di atas, didapatkan bahwa borderline perfusion terjadi pada usia 56-65 tahunsebanyak 2 orang $(100 \%)$.

Bahjatun Nadrati"Program Studi D.III Keperawatan STIKES YARSI Mataram, Indonesia Email: bahjatun.nadrati.bn@gmail.com

Zuhratul Hajri ${ }^{2}$ Program Studi D.III Keperawatan STIKES YARSI Mataram, Indonesia. Email: riehajri@gmail.com Sri Suharti ${ }^{3}$ Akademi Keperawatan Baitul Hikmah Bandar Lampung, Indonesia. Email: srisuhartil977@gmail.com 
GAMBARAN NILAI ANKLE BRACHIAL INDEX (ABI) PADA PENYANDANG DM TIPE 2 DI PUSKESMAS GUNUNGSARI LOMBOK BARAT

Tabel 7. Distribusi Frekuensi Nilai ABI Kanan Penyandang DM berdasarkan Jenis Kelamin $\mathrm{N}=25$

\begin{tabular}{ccccccc}
\hline Usia & \multicolumn{3}{c}{ ABI Kanan } & \multirow{2}{*}{ Total } \\
\cline { 2 - 5 } & \multicolumn{1}{c}{ Normal } & \multicolumn{3}{c}{$\begin{array}{c}\text { Borderlin } \\
\mathbf{e} \\
\end{array}$} & \multicolumn{5}{c}{ perfusion } \\
\cline { 2 - 6 } & $\mathbf{f}$ & $\%$ & $\mathbf{f}$ & $\%$ & $\mathbf{F}$ & $\%$ \\
\hline Perempuan & 15 & 68,2 & 2 & 66, & 17 & 68,0 \\
& & & 7 & & \\
Laki-laki & 7 & 31,8 & 1 & 33, & 8 & 32,0 \\
& & & 3 & & \\
Total & $\mathbf{2 2}$ & $\mathbf{1 0 0}$ & $\mathbf{3}$ & $\mathbf{1 0 0}$ & $\mathbf{2 5}$ & $\mathbf{1 0 0}$ \\
\hline
\end{tabular}

Dari tabel 7 di atas, didapatkan bahwa borderline perfusion terjadi pada responden perempuan sebanyak 2 orang $(66,7 \%)$.

Tabel 8. Distribusi Frekuensi Nilai ABI Kiri Penyandang DM Berdasarkan Jenis Kelamin N=25

\begin{tabular}{ccccccc}
\hline Usia & \multicolumn{4}{c}{ ABI Kanan } & \multirow{2}{*}{ Total } \\
\cline { 2 - 5 } & Normal & \multicolumn{3}{c}{$\begin{array}{c}\text { Borderline } \\
\text { perfusion }\end{array}$} & \\
\cline { 2 - 6 } & $\mathbf{f}$ & $\%$ & $\mathbf{f}$ & $\%$ & $\mathbf{F}$ & $\%$ \\
\hline Perempuan & 15 & 65,2 & 2 & 100 & 17 & 68,0 \\
Laki-laki & 8 & 34,8 & 0 & 0 & 8 & 32,0 \\
Total & $\mathbf{2 3}$ & $\mathbf{1 0 0}$ & $\mathbf{2}$ & $\mathbf{1 0 0}$ & $\mathbf{2 5}$ & $\mathbf{1 0 0}$ \\
\hline
\end{tabular}

Dari tabel 9 di atas, didapatkan bahwa borderline perfusion terjadi pada responden perempuan sebanyak 2 orang $(100 \%)$.

\section{PEMBAHASAN}

Berdasrakan tabel 4.3 dan 4.4 nilai $\mathrm{ABI}$ kanan dan kiri pada penderita DM berada pada nilai normal sebanyak 22 responden $(88 \%)$ dan 23 responden $(92 \%)$. Sementara itu 3 responden (12\%) mengalami borderline perfusion $\mathrm{ABI}$ kanan dan 2 responden ( $8 \%)$ mengalami borderlineperfusion $\mathrm{ABI}$ kiri. Dan dalam hasil penelitian ini tidak terdapat responden yang memiliki nilai interpertasi $A B I$ iskemik berat dan dan iskemik kaki kritis. Hasil penelitian ini sejalan dengan penelitian (Pratomo dan Apriyani, 2018) yang menunjukan bahwa dari total 98 responden 76 responden $(77,5 \%)$ menunjukan nilai $\mathrm{ABI}$ yang normal, borderline perfusion 22 responden $(22,5 \%)$ dan tidak ada stu respondenpun yang mengalami iskemik berat dan iskemik kaki kritis.

$A B I$ adalah parameter yang umumya digunakan untuk evaluasi menyeluruh status ekstremits. Ini didukung oleh hasil penelitian C.-F., Chang., et al (2013) membuktikan bahwa $A B I$ merupakan alat skiring kaki yang digunakan untuk mendeteksi awal adanya neurovaskulopati diabetikum. Selain itu juga, pengukuran nilai $A B I$ bertujuan untuk mendeteksi adanya insufisiensi arteri sehingga dapat diketahui adanya gangguan pada aliran darah menuju kaki, serta mendeteksi kemungkinan adanya penyakit arteri perifer/ peripheral arteri desease (PAD) pada kaki $(0,2004)$.

Interpretasi $\mathrm{ABI}$ yang normal menunjukan bahwa darah masih bersirkulasi dengan baik, tanpa adanya obstruksi yang bermakna pada pembuluh darah perifer, sehingga kebutuhan nutrisi dan oksigen pada ektremitas bawah dapat terpenuhi dengan baik. Kondisi interpretasi normal $\mathrm{ABI}$ pada responden dikarenakan penderita DM di Puskesmas Gunungsari mengikuti program rutin puskesmas yaitu senam DM. Senam DM merupakan salah satu bentuk latihan fisik, dimana efek latihan adalah menurunkan kadar glukos

Bahjatun Nadrati"Program Studi D.III Keperawatan STIKES YARSI Mataram, Indonesia Email: bahjatun.nadrati.bn@gmail.com

Zuhratul Hajri ${ }^{2}$ Program Studi D.Ill Keperawatan STIKES YARSI Mataram, Indonesia. Email: riehajri@gmail.com Sri Suharti ${ }^{3}$ Akademi Keperawatan Baitul Hikmah Bandar Lampung, Indonesia. Email: srisuhartil977@gmail.com 
darah, memperbaiki sirkulasi darah, meningkatkan pengambilan glukosa oleh otot, dan memperbaiki pemakaian insulin (Kuswandi, Sitorus \& Gayatri 2008; Jerau \& Arift, 2016; Dinata, 2015).

Sedangkan pada interpretasi borderline perfusion pada penderita DM menujukan berisiko dua hingga tiga kali lipat mengalami sumbatan pembuluh darah perifer berupa PAD dibandingkan pasien non DM (Sihombing \& Tuminah, 2015; Oktaviana, Sanjaja \& Salim, 2013). Penderita DM juga mengalami perubahan elastisitas pembuluh darah, penebalan dinding pembuluh darah dan pembentukan plak atau trombus yang menyebabkan vaskularisasi ke perifer terhambat (Pratomo dan Apriyani, 2018). Borderline perfusion terjadi pada usia 56 - 65 tahun (lansia akhir), sebanyak 2 responden $(66,7 \%)$ interpretasi $A B \mid$ kanan dan 2 responden (100\%) pada interpretasi $\mathrm{ABI}$ kiri. Hal ini dikarenakanp proses penuan mengakibatkan perubahan dinding pembuluh darah sehingga mempengaruhi transportasi oksigen dan nutrsi kejaringan. Perubahan tersebut mengakibatkan kekakuan pembuluh darah yang mengakibatkan peningkatan tekanan pembuluh darah perifer, gangguan aliran darah dan meningkatkan kerja ventrikel kiri (Riyanto, 2017; Eriana, 2017).

\section{SIMPULAN DAN SARAN}

Penyandang DM terbanyak dialami oleh perempuan dan sebagian besar penyandang DM memilki nilai $\mathrm{ABI}$ normal. Penyandang $\mathrm{DM}$ terbanyak pada pada usia 46-55 tahun. Berdasarkan jenis kelamin penyandang DM yang memilki nilai interpretasi Borderline perfusiadalah perempuan. Sedangkan adri usia penyandang DM dengan Borderline perfusi terjadi pada usia $56-65$ tahun.

Dalam upaya untuk meningkatkan derajat kesehatan masyarakat khususny penyandang DM diharapkan Puskesmas Gunung sari Kabupaten Lombok Barat, dapat mengontrol penyandang DM dalam mengikuti program puskesmas khusnya DM dan melibatkan keluarga berpartisipasi aktif memberikan dukungan kepada penyandang DM.

Dalam memberikan pelayanan keperawatan, perawat diharapkan dapat menjadikan senam DM sebagai penatalaksanan untuk mencegah PVD.

Diharapakan dapat menjadi refrensi tambahan bagi pendidikan dengan menjadikan gambaran $A B I$ pada penyandang DM sebagai dsar pengembangan intervensi keperawatan dengan kasus laian yang berhungan dengan $\mathrm{ABI}$.

Bagi peneliti selanjutnya, diharapkan penelitian ini dapat dijadikan acuan dalam penelitian lain yang berhubungan dengan gambaran $A B I$ pada penyandang DM. Dan hendaknya menggunakan responden yang lebih banyak serta menambahkan variabel lain yang berhubungan dengan penyandang $\mathrm{DM}$.

\section{DAFTAR PUSTAKA}

Amalia, S. (2016). Studi penggunaan obat analgesik pada pasien diabetik neuropati di rumah sakit universitas airlangga (rsua) surabaya (Doctoral dissertation, Universitas Airlangga).

Apriliyana, U. (2015). Pemberian Relaksasi Benson Terhadap Penurunan Nyeri Pada Asuhan Keperawatan Tn. W Dengan Pasca Bedah Benigna Prostat Hyperplasia Di Ruang Mawar II RSUD Dr. Moewardi Surakarta.

Betteng, R. (2014). Analisis Faktor Resiko Penyebab Terjadinya Diabetes Melitus Tipe 2 Pada Wanita Usia Produktif Dipuskesmas Wawonasa. Jurnal e-Biomedik, 2(2).

Chang, C. F., Chang, C. C., \& Chen, M. Y. (2015). Effect of Buerger's exercises on improving peripheral circulation: A systematic review. Open Journal of Nursing, 5(02), 120.

Dinata, W. W. (2015). Menurunkan Tekanan Darah Pada Lansiamelalui Senam Yoga. Jorpres (Jurnal Olahraga Prestasi), 11(2).

Ghani, L., Susilawati, M. D., \& Novriani, H. (2016). Faktor Risiko Dominan Penyakit Jantung Koroner di Indonesia. Indonesian Bulletin of Health Research, 44(3), 153-164.an Konsumsi Obat Antidiabetik dengan Kadar Gula Darah pada Penderita diabetes Melitus Tipe 2 di rS QIM Batang Tahun 2013. Unnes Journal of Public Health, 4(2)..

Bahjatun Nadrati"Program Studi D.IIl Keperawatan STIKES YARSI Mataram, Indonesia Email: bahjatun.nadrati.bn@gmail.com

Zuhratul Hajri ${ }^{2}$ Program Studi D.IIl Keperawatan STIKES YARSI Mataram, Indonesia. Email: riehajri@gmail.com Sri Suharti ${ }^{3}$ Akademi Keperawatan Baitul Hikmah Bandar Lampung, Indonesia. Email: srisuhartil977@gmail.com 
GAMBARAN NILAI ANKLE BRACHIAL INDEX (ABI) PADA PENYANDANG DM TIPE 2 DI PUSKESMAS GUNUNGSARI LOMBOK BARAT

Jerau, E. E., \& Arif, S. (2016). Efektivitas senam kaki diabetik dan senam ergonomik terhadap penurunan kadar glukosa darah pasien diabetes melitus di Persadia RS Panti Wilasa Citarum. Karya IImiah.

Kementrian Kesehatan Republik Indonesia. (2007). Laporan Hasil Riset Kesehatan Dasar (Riskesdas) Nasional 2007. Jakarta: Badan Litbangkes, Depkes RI.

Kuswandi, A., Sitorus, R., \& Gayatri, D. (2008). Pengaruh relaksasi terhadap penurunan kadar gula darah pada pasien diabetes mellitus tipe 2 di sebuah rumah sakit di Tasikmalaya. Jurnal Keperawatan Indonesia, 12(2), 108-114.

McMaster Universities, O. A. (2004). Matters arising. Ann Rheum Dis, 63, 750-754.

Mongisidi, G. (2014). Hubungan Antara Status SosioEkonomi dengan Kejadian Diabetes Melitus Tipe 2 Di Poliklinik Interna Blu Rsup Prof. Dr. RD Kandou Manado

Oemiyati, R., \& Rustika, R. (2015). Faktor Risiko Penyakit Jantung Koroner (Pik) Pada Perempuan (Baseline Studi Kohor Faktor Risiko Ptm)(Risk Factors for Coronary Heart Disease (Chd) in Women [Baseline Cohort Study of Risk Factors for Non Communicable Disease]). Buletin Penelitian Sistem Kesehatan, 18(1), 47-55.

Oktavian, A., Sandjaja, B., \& Salim, L. (2013). Sindroma Metabolik di Kota Jayapura. Indonesian Bulletin of Health Research, 41(4).

Pratomo, I. B., \& Apriyani, H. (2018). Ankle Brachial Index (ABI) Pada Penderita DM Tipe 2 di Puskesmas Kabupaten Lampung Utara. Jurnal IImiah Keperawatan Sai Betik, 14(1), 30-34.

Putri, N. H. K., \& Isfandiari, M. A. (2013). Hubungan empat pilar pengendalian $\mathrm{dm}$ tipe 2 dengan rerata kadar gula darah. Jurnal Berkala Epidemiologi, 1(2), 234-243.
Rahayu, E., Kamaluddin, R., \& Sumarwati, M. (2014). Pengaruh Program Diabetes Self Management Education Berbasis Keluarga Terhadap Kualitas Hidup Penderita Diabetes Melitus Tipe II

Rahayu, V. E. S., Yasa, I. D. P. G. P., \& Widastra, I. M. (2014). Status fungsional pasien diabetes melitus tipe II Di Rumah Sakit Umum Pusat Sanglah Denpasar. Jurnal Skala Husada Volume 11Nomor, 29, 33.

Rahmaningsih, B. Y., Nur Hidayat, S. P., lin Novita, N. M., \& PD, S. (2016). Hubungan antara nilai ankle brachial index dengan kejadian diabetic foot ulcer pada penderita diabetes melitus tipe 2 di RSUD Dr. Moewardi Surakarta (Doctoral dissertation, Universitas Muhammadiyah Surakarta).

Restuningtyas, A.(2016). Pengaruh Kombinasi Perawatan Luka Modern Dengan Ozon Bagging Terhadap Proses Penyembuhan Ulkus Kaki Diabetik Pada Klien Diabetes Melitus Di Rumah Rawat Luka Nirmala Jember.

Riyanto, I. (2017). Hubungan kepatuhan senam diabetes melitus dengan Ankle Brachial Index (ABI) pada pasien diabetes melitus Tipe $2 \mathrm{Di}$ Puskesmas Randudongkal Kabupaten Pemalang Tahun 2017 (Doctoral dissertation, Muhammadiyah University of Semarang).

Suriya, M. (2016). Pengaruh senam diabetes melitus dengan nilai abi pada pasien $\mathrm{dm}$ di puskesmas andalas padang. Pengurangan Resiko Bencana, 68.

Vitani, R. A. I. (2015). Tinjauan Literatur: Musik Sebagai Intervensi Untuk Pasien Postoperasi. Proceedin, 250

Wahyuni, T. D. (2015). Ankle Brachial Index (ABI) sesudah senam kaki diabetes pada penderita diabetes melitus tipe 2. Jurnal Keperawatan, 4(2).

Bahjatun Nadrati"Program Studi D.III Keperawatan STIKES YARSI Mataram, Indonesia Email: bahjatun.nadrati.bn@gmail.com

Zuhratul Hajri ${ }^{2}$ Program Studi D.IIl Keperawatan STIKES YARSI Mataram, Indonesia. Email: riehajri@gmail.com Sri Suharti ${ }^{3}$ Akademi Keperawatan Baitul Hikmah Bandar Lampung, Indonesia. Email: srisuhartil977@gmail.com 
GAMBARAN NILAI ANKLE BRACHIAL INDEX (ABI) PADA PENYANDANG DM TIPE 2 DI PUSKESMAS GUNUNGSARI LOMBOK BARAT

Widyawati, I. Y., Irawaty, D., \& Sabri, L. (2017). Active Lower Range of Motion Reduce the Sign and Symptom of Diabetic Neuropathy. Jurnal Ners, 5(2), 107-117.

WOCN, C. P. W. S. (2012). Ankle Brachial Index: quick reference guide for clinicians. Journal of wound, ostomy, and continence nursing: official publication of The Wound, Ostomy and Continence Nurses Society, 39(2 Suppl), S21.
Wulandari, O., \& Martini, S. (2013). Perbedaan kejadian komplikasi penderita diabetes melitus tipe 2 menurut gula darah acak. Jurnal Berkala Epidemiologi, I.

Yuliani, F., Oenzil, F., \& Iryani, D. (2014). Hubungan berbagai faktor risiko terhadap kejadian penyakit jantung koroner pada penderita diabetes melitus tipe 2. Jurnal Kesehatan Andalas, 3(1).

Bahjatun Nadrati"Program Studi D.Ill Keperawatan STIKES YARSI Mataram, Indonesia Email: bahjatun.nadrati.bn@gmail.com

Zuhratul Hajri ${ }^{2}$ Program Studi D.III Keperawatan STIKES YARSI Mataram, Indonesia. Email: riehajri@gmail.com Sri Suharti ${ }^{3}$ Akademi Keperawatan Baitul Hikmah Bandar Lampung, Indonesia. Email: srisuhartil977@gmail.com 